\title{
Petri Net-Based R\&D Process Modeling and Optimization for Composite Materials
}

\author{
Xiaomei Hu, Lei Zhao, and Wenlong Li \\ The Key Laboratory of Machinery Automation and Robotics, School of Mechatronic Engineering and Automation, Shanghai University, \\ Mailbox 232, No. 149 Yanchang Road, Shanghai 200072, China
}

Correspondence should be addressed to Xiaomei Hu; sufeimasohxm@163.com

Received 7 June 2013; Accepted 27 August 2013

Academic Editor: Chong Lin

Copyright (C) 2013 Xiaomei Hu et al. This is an open access article distributed under the Creative Commons Attribution License, which permits unrestricted use, distribution, and reproduction in any medium, provided the original work is properly cited.

Considering the current R\&D process for new composite materials involves some complex details, such as formula design, specimen/sample production, materials/sample test, assessment, materials/sample feedback from customers, and mass production, the workflow model of Petri net-based R\&D process for new composite materials' is proposed. By analyzing the time property of the whole Petri net, the optimized model for new composite materials R\&D workflow is further proposed. By analyzing the experiment data and application in some materials R\&D enterprise, it is demonstrated that the workflow optimization model shortens the period of R\&D on new materials for $15 \%$, definitely improving the R\&D efficiency. This indicates the feasibility and availability of the model.

\section{Introduction}

New materials, as the foundation and guide of new advanced technology, have become the most important field with great potential for future development. For materials production enterprise, possessing the ability to develop and produce new materials and building up innovation system are dispensable processes to cultivate the spirit of innovation for their brand. Because the process innovation has become part of technique innovation, it is more likely to make enterprise grow steadily. While an enterprise faces the venture from competition in an open market, targeting at the key business and then reducing the venture in competition in process innovation, perceiving the new business pattern, and creating business value have become an efficient way for enterprise's growth. Above all, the process innovation is not only significant in improving the efficiency of key business but also can help enterprises gain the opportunity of promoting value together in cooperation under the trend that market has become flat, which is caused by globalization.

For materials production enterprise, the ability of production $R \& D$ determines its core competitiveness. The R\&D process of new composite materials involves component design, specimen/sample production, materials/sample test, assessment, materials/sample feedback from customer, mass production, and so forth. All the processes are related to departments like production, design, test, store management, sales, and so forth. In the process of new composite materials $\mathrm{R} \& \mathrm{D}$, actions and steps are not simultaneous; they are happening with sequence. How to organize and manage all these steps effectively and regulate human resource and information in unit are main tasks of automation for assignment process. In a word, adopting workflow technique to standardization management for process of new composite materials R\&D standard can strengthen the innovative power of materials producing enterprise effectively.

Petri net can express the static structure and dynamic behavior of system very well. So Petri net theory has been applied in model building, analyzing, and controlling in all fields [1-5]. Method of Petri net-based workflow modeling is a quite active field to be studied [6-13]. By applying Petri net model into new composite materials R\&D workflow modeling and giving full play to the excellent mathematic features of Petri net, the workflow model can be well established, tested, and verified. 


\section{Related Work}

2.1. Workflow Technology. Workflow technology dates back to the middle of 1970 s in the study of office automation field, and the primitive business system involving workflow has appeared in the image processing and E-mail field from 1983 to 1985 . Since 1990s, with the popularization of personal computer and internet technology and also the gradually perfection of informatization construction, the workflow technology R\&D has become a new popular trend. Besides, the workflow technology [14-18] has been accepted since 21st century, and the standard, workflow engine, and other business production which are related to it are countless. While people are developing and spread the workflow production, the study of workflow theory is also well concerned, to prompt the maturity of this technology.

The development of workflow technology is relatively mature out of China. Some famous workflow business software suppliers continue to produce new production; among them are some famous enterprise-class workflow production like WLI (WebLogic Integration Studio) from BEA, holosofx and MQSeries workflow from IBM, IFlow form Fujitsu, NetWeaver from SAP, and Orchestration Server from Sonic. In particular, the Web-based workflow system, which means accomplishing task cooperation by WWW, has become a new trend in market, and the business process management production from Ultimus is one of the representative products.

In China, some influential business workflow system developing company including SynchoFlow has reached the leading level in its definition of process. Compared with other countries in the world, the R\&D of workflow technology in China still needs to be improved. So some universities in China have taken the workflow technology as study subject; for example, Professor Fan Yushun from Tsinghua University designed and developed the CIMFlow workflow management system, proposing the CIMFlow workflow model; Zhejiang University developed WPDL (Workflow Process Definition Language), accomplishing workflow modeling support platform, and they all made great research progress.

The workflow technology was first applied in image processing and E-mail field mainly. After 1990s, enterprises in different industries all realized the importance of informatization construction and that using workflow technology to model business process should be applied in construction of informatization management system. So the workflow modeling gradually became an important part of process management system. What is more, composite materials industry was also aware of the significance of integrated R\&D process management system and ready to build their own enterprise informatization systems. However, almost all of the enterprises are at beginning, and there is a long way to go before being mature. Therefore, even though workflow technology is applied in nearly every industry, it is just in the starting step in the application of composite materials production enterprises.

2.2. Petri Net Technology. Petri net, invented by Carl Adam Petri in the 1960s, was a tool for modeling and analyzing of distributed system and used to describe relationships among order, concurrency, conflict, and synchronization in process or task in the system. Having been developing for fifty years, Petri net is applied in many science technology areas such as computer science technology, automatic science technology, mechanical design and manufacture. The reason is that Petri net not only has rich expressions for workflow management system and a plenty of analyzing technology and dynamic features but also is intuitive and easy to learn as it is a graphic language.

On the one hand, Petri net can express the system structure and system dynamic behavior with graph; on the other hand, it can be analyzed quantificationally by mathematic methods. Prototype of Petri net includes three elements: " $P$ " is a status element, named Place, considered to be requirement, position, resource, waiting on line, channel, and so forth in reality; " $T$ " is a transition element, named Transition, again to be regarded as occurrence, transition, movement, executing of language, sending/receiving messages, and so forth, in reality; " $F$ " is connection between $P$ and $T$; Token is resource amount that a Place includes. Definition of basic $P N$ can be described with four members, as follows:

$$
\mathrm{PNS}=\left(P, T, I, O, m_{0}\right)
$$

(1) $p=\left\{p_{b}, \ldots, p_{n}\right\}$ is finite set of Place, with $n>0$ being the number of Place;

(2) $T=\left\{t_{1}, \ldots, t_{n}\right\}$ is finite set of Transition, with $m>0$ being number of Transition;

(3) $I: P \times T \rightarrow N$ is input function; it defines the repetition of connection or set of weight from $P$ to $T$. $N=\{0,1, \ldots\}$ is set of nonnegative integers here;

(4) $O: T \times P \rightarrow N$ is output function; it defines repetition of directed arc or set of weight from $T$ to $P$;

(5) $m_{0}$ is initial marking.

Basic Petri net can take statues, occurrence, synchronization, concurrency, choice, and recycle for modeling but not data and time. Additionally, with the increasing of complexity in real process, the elements that made up model would augment in number apparently, making the model excessively large. To solve these problems, expansion on classic Petri net is proposed, named high-level Petri net. Because basic Petri net has some limitation in simulation ability and understandability, prompting the extended form of basic Petri net to appear. In general, it can be divided into three types: timed Petri net, stochastic Petri net, and colored Petri net [19-26].

In practical situation, only one form of Petri net usually is not enough to express and describe relative complex system. Under this circumstance, it is necessary to combine several Petri net. Consequently not only disadvantages of one particular Petri net can be overcome, but also the expressing and describing ability of whole Petri net can be extended. Thus, nowadays the Petri net and its advanced form can mainly satisfy the requirement of most complex model.

A good system model should possess not only powerful simulation ability but also abundant analysis methods. 
Having been developing for more than 50 years, many comparative mature analysis methods have come into being, among which have some more intuitive graphic analysis methods and also some powerful algebraic analysis methods. This would provide convenience to analyze properties of Petri net model and then optimize the model. Thus, Petri net has been applied widely in many study areas of computer science, such as communication field, distributed software modeling and analyzing, software engineering, parallel programming, memory system with multiprocessor, decision supporting, and system properties evaluating $[27,28]$.

\section{Petri Net-Based R\&D Process Modeling for New Composite Materials}

3.1. Standardization of R\&D Process for New Composite Materials. Main steps of R\&D process for new composite materials include application for R\&D project, approval of project, determination of project materials' brands, formula design, color design, specimen production and test, specimen feedback, and storage, which involve functional department such as R\&D department, quality department, purchase department, sell department, market department, and so forth. A huge amount of forms and data will be used in those steps. However, managing R\&D technology by defining workflow model of new specimen production can make division of labor clear and cooperation orderly. There is hierarchical process while developing new production, as to support the complex business process; extended interface of workflow engine is studied and defined, then realizing the workflow management system function that supports the $R \& D$ for technology management process defining. Production R\&D workflow is divided into 5 parts by the system: applying evaluation of workflow, examining and approving formula/technology and planning and constructing workflow, confirming production quality and testing workflow, testing and judging and putting into workflow, delivering and customer feedback workflow. The integrated process of new composite materials $\mathrm{R} \& \mathrm{D}$ is shown in Figure 1.

3.1.1. Applying Workflow Evaluation. First, new customers and projects before developing new composite materials should be established in order to centralize manage customers and project documents conveniently. And then, part of content of design and development applying form should be filled out, which means establishing development applying form-those are done by clerks. Next, they are submitted to business manager/business director to approve, or handed to manager of market department if necessary. Thus, manager of market department can know some related information of customers and market news immediately. After that, colormatching supervisor determines the delivering deadline and color according to the request from customers, and distributes the application form to developers. The developers confirm properties' requirement from customers, and second confirmation should be done by development manager if

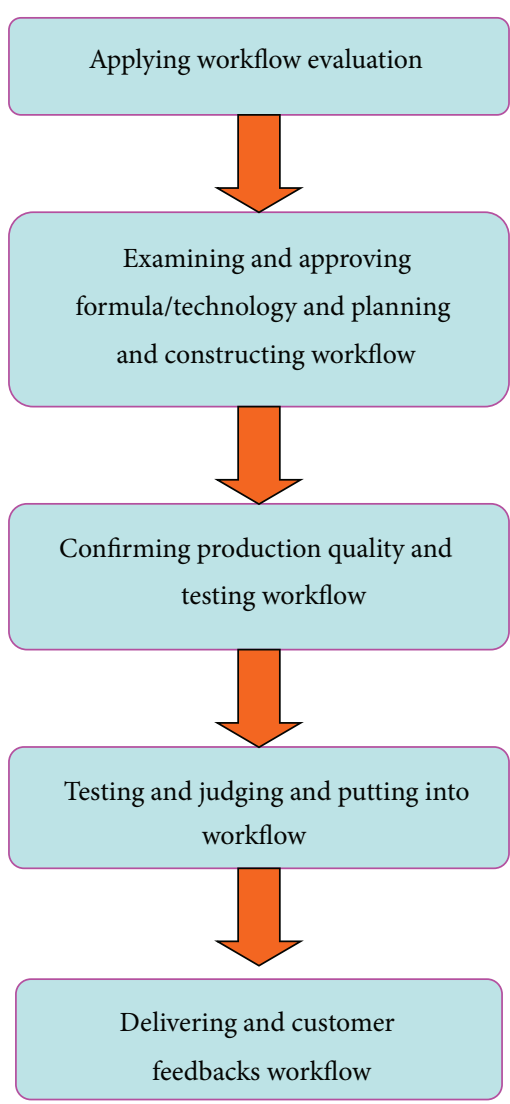

FIGURE 1: Entire flow chart of new composite materials R\&D.

necessary. Finally, the system goes into the examining and approving formula/technology and planning and constructing workflow. The flow chart is shown in Figure 2.

3.1.2. Examining and Approving Formula/Technology and Planning and Constructing Workflow. In this workflow, based on certain properties requirements of materials, developer and development manager determine the specific formula and component of each material, specific testing project which needs to insert quality testing, and relevant note information. Then, they construct and determine process information. After that application form is submitted to the development manager/director to audit the material formula and process information. It is only audited here, not to modify the content at random. If they can not be approved, then some related note information should be filled out, and meanwhile go back to a last process to be dealt with. On the contrary, if approved, they would be handed to color-matching supervisor to produce and test plan construction, and supervisor will determine number according to the requirement of the color. Next, colormatching technician and materials technician will make up specific color formula and get everything ready before production. Finally, the system goes into "validating production quality and testing workflow." The flow diagram is shown in Figure 3. 


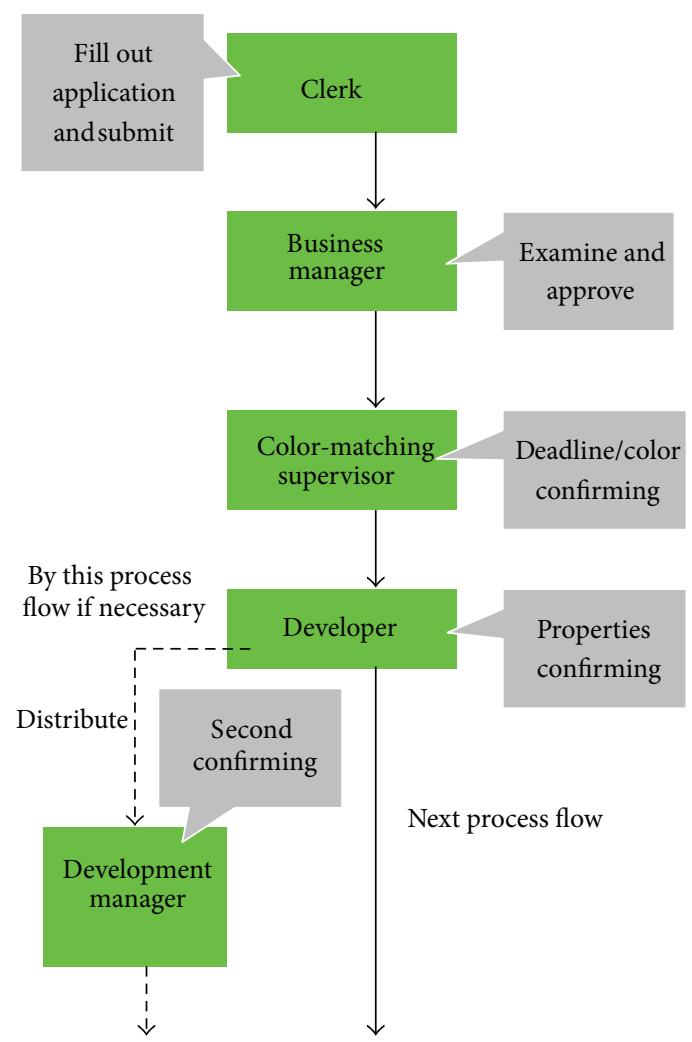

FIGURE 2: Flow chart of applying workflow evaluation.

3.1.3. Validating Production Quality and Testing Workflow. In the process of production, color-matching technician and sample record each link of specific production process, check out the entire production process, and record test results. After sample producing, color-matching supervisor is in charge of correcting sample color, evaluating the cost of color formula and materials formula, and rechecking production process record made by color-matching technicians, ensuring normalization of sample production process. And then to test the sample products test supervisor makes a specific test plan; then, testers test products and input those property parameters into system. The flow diagram is shown in Figure 4.

3.1.4. Testing and Judging and Putting into Workflow. In this workflow, testers confirm validity and integrality of tested property parameters and also validity of input first and then developers will check testing results. If necessary, the development manager/director will provide second confirmation, and, again, it is only confirmation, not to modify relevant testing results information. After testing is finished, clerk takes charge of storage procedure and it can be delivered to customers. Salesman will deal with the delivering procedures, if necessary; business office clerk can substitute for delivering procedure. But if testing failed, developers will record related information and then maintain materials formula information again while color-matching supervisor maintains color

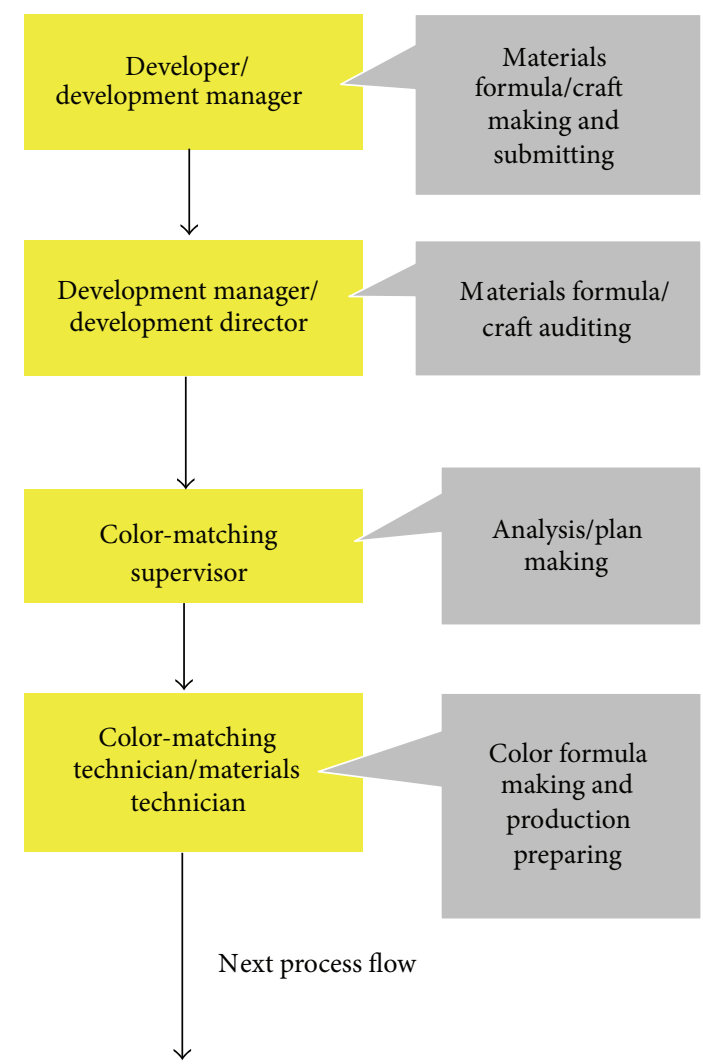

FIGURE 3: Flow chart of formula/technology and planning and constructing workflow.

formula information, to produce the sample again. The flow chart is shown in Figure 5.

3.1.5. Delivering and Customer Feedback Workflow. Salesman/business office clerk should confirm specific delivering information and submit it to business manager or interior ministry manager to approve after confirming its correctness. Delivering from warehouse can be done when it is approved, and the salesman should give feedback about customers' probation after that. The flow diagram is shown in Figure 6.

What has been listed above is the business process of entire $R \& D$ system. As to feedback, if customers are dissatisfied with the color or materials formula and need to modify them, developers should make modification and maintenance on materials formula; at the same time, R\&D manager also should make examination and verification. Besides, color-matching technicians maintain color formula; meanwhile color-matching supervisor should make examination and verification. What is more, developers need to edit and maintain technology specification, and the technology specification is edited by developers and examined and verified by $\mathrm{R} \& \mathrm{D}$ manager. Testers are accessible to make inquiry on technology specification. The process of examination and verification discussed above can only be examined and verified, confirmed, and filled out with note information, yet none of its specific information content can 
be modified. If results of examination and verification fail to meet requirement, it will go back to last process.

\subsection{Workflow Modeling of Petri Net-Based RઐD Process Management System}

3.2.1. Formalization Definition of Workflow. At first, the system creates business process-by-process definition tool and uses formalizing definition language to define all the necessary information which can be executed by workflow during business process, for example, the initial and terminal condition, scheduling discipline, and so forth. Then, workflow engine is used to manage and control information data of each activity in changing states in the system and this data is used to confirm the specific state transferring in workflow process. At the end, workflow management system can directly call application software or by application software agency.

Any workflow system models definite the process it supports, and these processes are the core unites in the system. During the procedure definition of control flow, each activity is connected by routing which is description of the time and order of each activity. Using building block ANDsplit, AND-join, OR-split, and OR-join, it can build activities in four forms: order routing, selective routing, paralleling routing, and looping routing.

(1) Order Routing. Activities must execute strictly by the order, as in Figure 7.

(2) Selective Routing. According to conformance achieved its requirements, activity chooses to execute one of two activities, as in Figure 8.

(3) Parallel Routings. It means two activities can execute randomly at same time, as in Figure 9.

(4) Looping Routing. It means when a specific condition is satisfied, an activity can be repeatedly executed one time or several times, as in Figure 10.

In specific composite materials $\mathrm{R} \& \mathrm{D}$ production process management system workflow model, different basic routings are connected through its input and output Place; complex system models can be made up. Therefore, according to the specific work process analysis of the manuscript management of each function module, using the four basic routings above and assembling them in certain logical relation can build complex composite materials $\mathrm{R} \& \mathrm{D}$ production process management system workflow model. The Petri net of control flow modeling for workflow is called workflow net (WF net).

\subsubsection{The Structure of Composite Materials R\&D Production} Flow Management System Workflow Net. By combining time Petri net and color Petri net and improving them, a new workflow net is proposed, CMRDPMWFN (composite materials R\&D production management workflow net). Specific definition is shown below.

Definition 1. Improving workflow CMRDPMWFN $=(P, T$, $F, M, K, D, I, O)$, includes the following.

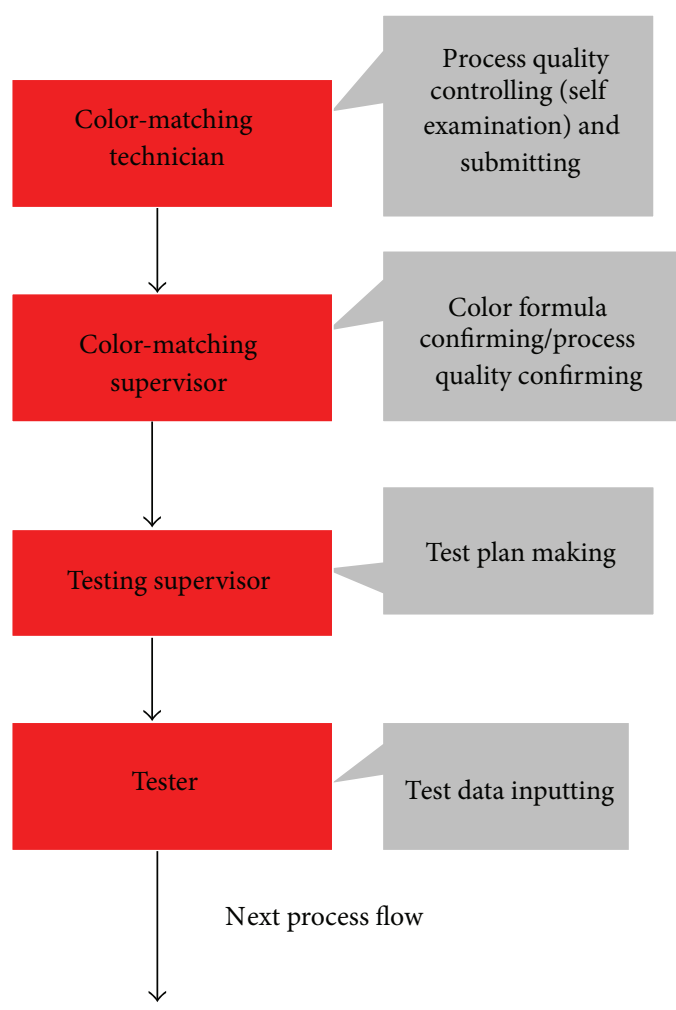

FIGURE 4: Flow chart of testing and judging and putting into workflow.

(1) $P=\left\{P_{1}, P_{2}, P_{3}, \ldots, P_{n}\right\}$ is the finite set of Place; $n>0$ is the number of Place.

(2) $T=\left\{T_{1}, T_{2}, T_{3}, \ldots, T_{n}\right\}$ is the finite set of Transition; $n>0$ is the number of the Transition.

(3) $F \subseteq(P \times T) \cup(T \times P)$ is the Cartesian product of $P$ and $T$ and also stands for a set of directed arc (states flow relationship).

(4) $M\left(m\left(P_{1}\right), m\left(P_{2}\right), \ldots, m\left(P_{n}\right)\right)$ is an $n$-dimensional vector and the identification of system, and $m_{0}$ is initial identification of the system.

(5) $K=\left(K_{1}, K_{2}, K_{3}, \ldots, K_{n}\right)$ is the token types, which can be regarded as a color of color Petri net.

(6) $D=\left(d_{1}, d_{2}, d_{3}, \ldots, d_{n}\right)$ is delay time set of all Transition; $d_{i}$ is the delay of $t_{i}$.

(7) $I: P \times T \rightarrow N$ is the input function; it defines the sets of repeated number or weight of the directed arc from $P$ to $T ; N=\{0,1, \ldots\}$ is nonnegative integer sets.

(8) $O: T \times P \rightarrow N$ is the output function; it defines the sets of repeated number or weight of the directed arc from $T$ to $P$, with $N=\{0,1, \ldots\}$ being nonnegative integer sets.

Applying the algorithm to the cases of composite materials $\mathrm{R} \& \mathrm{D}$ production process management system, analyzing all the events of the system, and according to the definition and algorithm above, combining each event and activity together based on the work control flow of the 


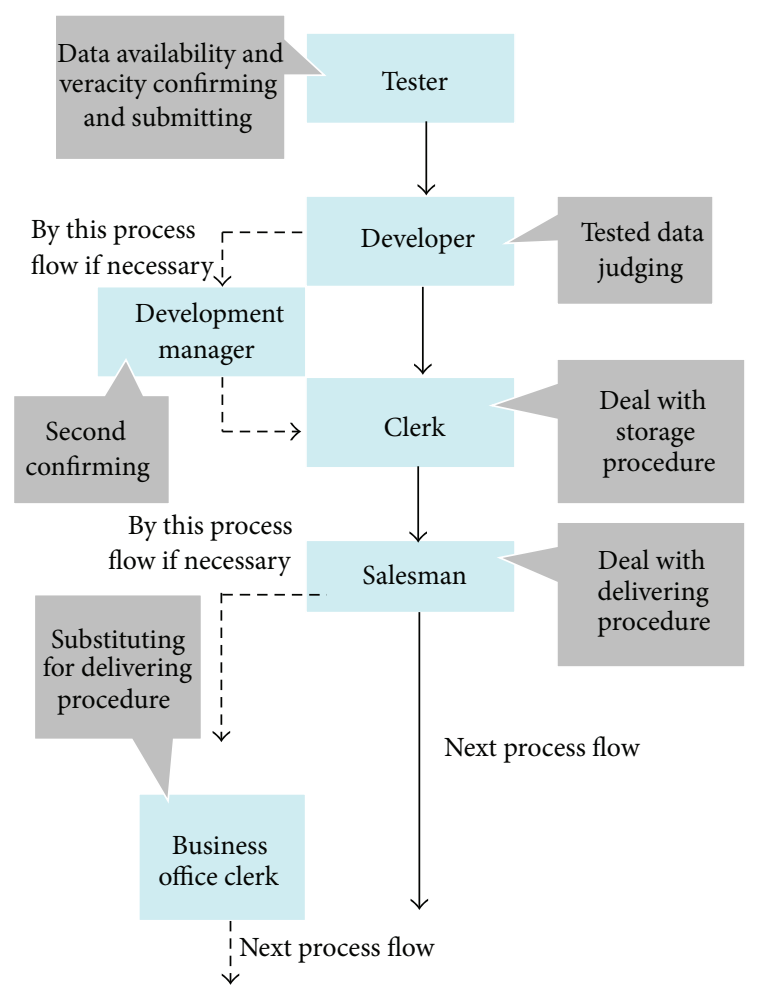

FIGURE 5: Flow chart of testing and judging and storage workflow.

system can construct composite materials research and development production process management workflow net (CMRDPMWFN).

3.2.3. Analysis of Executing Process. According to standardization of the composite materials $\mathrm{R} \& \mathrm{D}$ production process, the whole process can be divided into several steps: preparation at the beginning of $\mathrm{R} \& \mathrm{D}$, developing production, testing, warehousing, and so forth. Among them, the preparation at the beginning of $\mathrm{R} \& \mathrm{D}$ mainly includes market research, demand analysis, feasibility analysis, and feasibility audit. The whole Petri net will use the 42 Place with time to show the processed status of each task. The specific meanings of each Place are shown in Table 1.

Each Place uses transition with time to show the completion of task among Place. The whole process uses 41 Transitions to describe. Each Transition and its meaning are shown in Table 2.

According to the two forms and the relationship between each Place and Transition, Petri net is established which is shown in Figure 11; circles stand for Places, squares stand Transitions, and arrows stand for the connecting arc between Places and Transitions.

The entire composite materials $\mathrm{R} \& \mathrm{D}$ process flow starts moving from $P_{1}$, which means the beginning of the whole R\&D process, regardless of the movement pattern of the system it will reach $P_{33}$ eventually and finish as an end, which also marks the end of the whole $R \& D$ process. The whole process can be divided into several stages: previous

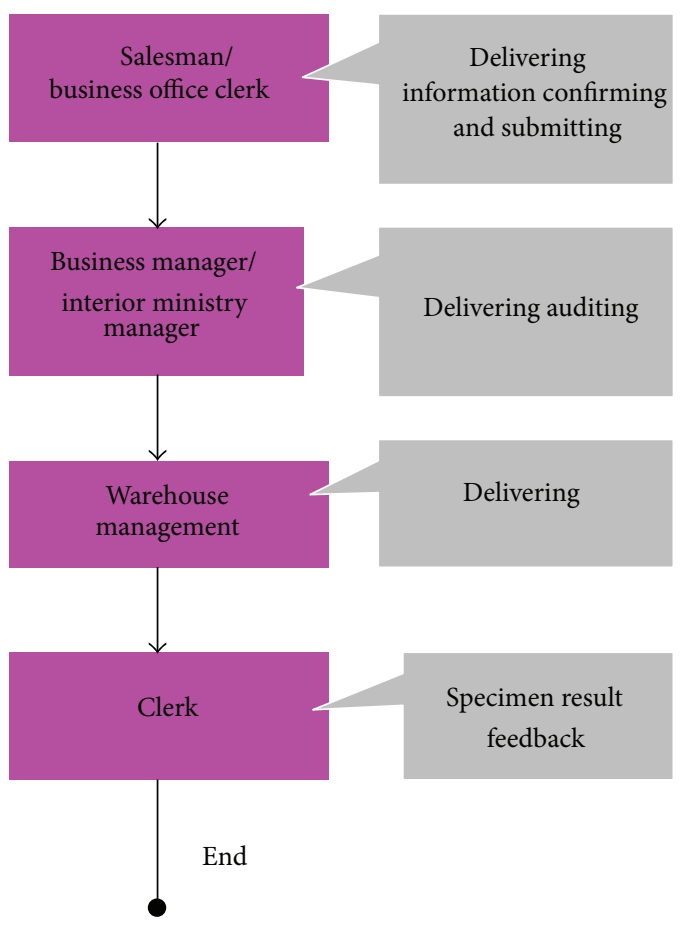

FIGURE 6: Flow chart of delivering and customer feedback workflow.

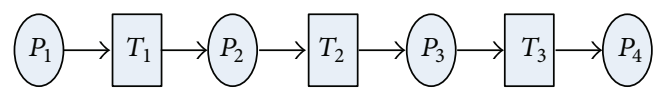

FIGURE 7: Order routing.

preparation stage, matching stage, production stage, testing stage, and follow-up clearing up stage.

Establishing workflow net directly and visually describes the specific direction of each flow and the changing situation of each state during the new composite materials $R \& D$ production process. By detailed analysis of the workflow net above, the specific process and each status of each section, the beginning of materials R\&D preparation stage, matching stage, production stage, testing stage, and follow-up clearing up stage can be seen very clearly.

\section{Petri Net Workflow Model Optimization in Composite Materials R\&D Production Process}

Analyzing technology of workflow model property is used to examine whether workflow model can meet requirement in terms of property; the main properties are throughput, temporal property, resource utilization rate, and so forth, the major concern is property analysis.

Because R\&D period of new composite materials determines enterprise's innovation ability, shorten $\mathrm{R} \& \mathrm{D}$ period will greatly improve their own competitiveness. Therefore, the temporal property is most concerned in this system. In this system, every Place stands for a single task, so temporal 


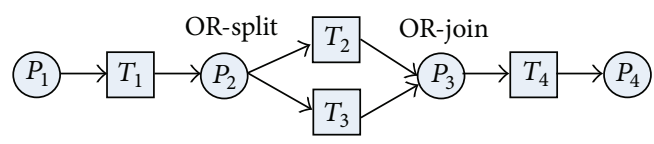

FIgURE 8: Selective routing.

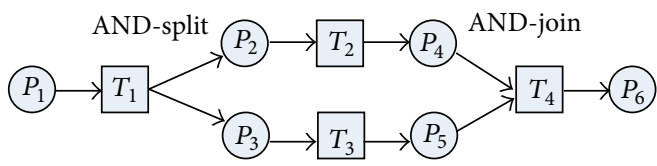

Figure 9: Paralleling routing.

bounds of every Place (task) need to be defined first except the first and last Place (see Table 3 ).

In Table 3, $E_{1}$ and $E_{2}$ stand for upper limit and lower limit of time of every Place. A Place stands for a process, and $E_{1}$ stands for possibly the minimum time spent after finishing the process, while $E_{2}$ stands for the maximum time spent. $L_{1}$ and $L_{2}$ stand for minimum and maximum total time spent while the entire project is proceeding to this process. $L_{1}$ stands for minimum total time, or time that the fast process needs, while $L_{2}$ stands for maximum total time or time that the process must finish at latest.

According to the calculation, if every task finishes by its minimum time of the project, the minimum time of entire project is 110 days. On the contrary, if every task is finished by its maximum time of the project, the project can be finished in 155 days.

If the entire net is optimized, then time needed for the project will be greatly shortened. In the system, color matching and materials matching can be conducted separately. Hence, net of matching process can be optimized. Optimized Petri net model of matching process is shown in Figure 12. The meaning of each Transition and Place is the same, but a parallel net is just added.

Optimized Petri net model reduces a Transition $T_{16}$, yet other Transition and Place remain the same. The meaning of Transition $T_{13}$ changes, which is starting to confirm the color formula and materials formula. Transition $T_{19}$ will be triggered after Places $P_{16}$ and $P_{19}$ finish. Thus, parallel net is added.

To compute time that the entire system spends conveniently, matching process net should be simplified. Hypothetical $d_{1}$ stands for $P_{14}$ and $P_{17}, d_{2}$ stands for $P_{15}$ and $P_{18}, d_{3}$ stands for $P_{16}$ and $P_{19}, f_{1}$ stands for $T_{14}$ and $T_{17}, f_{2}$ stands for $T_{15}$ and $T_{18}$, and $f_{3}$ stands for $T_{38}$ and $T_{39}$. The simplified graph of matching process net is shown in Figure 13.

So now upper and lower time limit of each task are shown in Table 4.

In Table $4, d_{1}$ stands for maximum time needed in formula confirmation. Because time needed in materials property confirming and color confirming is the same there, property confirming time can be used; $d_{2}$ stands for maximum time needed in formula developing. Because time needed in materials property developing is longer than color developing, materials developing time can be used only;

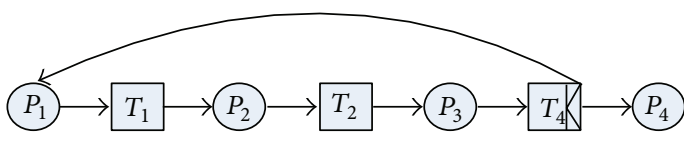

FIGURE 10: Looping routing.

TABLE 1: Name of Place and its meaning.

\begin{tabular}{|c|c|}
\hline Place & Meaning of Place \\
\hline$P_{1}$ & Preparation of new materials R \& D \\
\hline$P_{2}$ & Market research \\
\hline$P_{3}$ & Demand analysis \\
\hline$P_{4}$ & Feasibility analysis \\
\hline$P_{5}$ & Feasibility audit \\
\hline$P_{6}$ & Property analysis \\
\hline$P_{7}$ & Property confirmation audit \\
\hline$P_{8}$ & Set out technical specifications \\
\hline$P_{9}$ & The audit of technical specifications \\
\hline$P_{10}$ & Application of development application form \\
\hline$P_{11}$ & Approval of development application form \\
\hline$P_{12}$ & Distribution of development application form \\
\hline$P_{13}$ & Preparing formula \\
\hline$P_{14}$ & Material formula performance confirmation \\
\hline$P_{15}$ & Material formula research and development \\
\hline$P_{16}$ & Audit of material formula results \\
\hline$P_{17}$ & Color formula requirements confirmation \\
\hline$P_{18}$ & Color formula research and development \\
\hline$P_{19}$ & Audit of color formula results \\
\hline$P_{20}$ & Confirmation technology parameters \\
\hline$P_{21}$ & Set out technology parameters \\
\hline$P_{22}$ & Audit technology parameters \\
\hline$P_{23}$ & The preparation of the production plan \\
\hline$P_{24}$ & Ready to production \\
\hline$P_{25}$ & Production \\
\hline$P_{26}$ & Set out test plan \\
\hline$P_{27}$ & Entry of test data \\
\hline$P_{28}$ & Judge the validity and correctness of test data \\
\hline$P_{29}$ & Test \\
\hline$P_{30}$ & Judge test results \\
\hline$P_{31}$ & Deal with storage \\
\hline$P_{32}$ & Collect data document and warehousing \\
\hline$P_{33}$ & Project ends \\
\hline
\end{tabular}


TABLE 2: Name of transition and its meaning.

\begin{tabular}{|c|c|c|c|}
\hline Transition & Meaning of transition & Transition & Meaning of transition \\
\hline$T_{1}$ & Market researching & $T_{22}$ & $\begin{array}{l}\text { Technology parameters auditing } \\
\text { finished, start preparing } \\
\text { production plan }\end{array}$ \\
\hline$T_{2}$ & $\begin{array}{l}\text { Market research finished, } \\
\text { demand analyzing }\end{array}$ & $T_{23}$ & $\begin{array}{l}\text { Production planning establishing } \\
\text { finished, start preparing } \\
\text { production }\end{array}$ \\
\hline$T_{3}$ & $\begin{array}{l}\text { Demand analyzing finished, } \\
\text { feasibility analyzing }\end{array}$ & $T_{24}$ & $\begin{array}{l}\text { Production preparing finished, } \\
\text { start producing }\end{array}$ \\
\hline$T_{4}$ & $\begin{array}{l}\text { Feasibility analyzing finished, } \\
\text { feasibility approving }\end{array}$ & $T_{25}$ & $\begin{array}{l}\text { Producing finished, start } \\
\text { preparing for test plan making }\end{array}$ \\
\hline$T_{5}$ & $\begin{array}{l}\text { Feasibility approving is eligible, } \\
\text { property analyzing }\end{array}$ & $T_{26}$ & $\begin{array}{l}\text { Test plan establishing finished, } \\
\text { start inputting test data }\end{array}$ \\
\hline$T_{6}$ & $\begin{array}{l}\text { Property analyzing finished, } \\
\text { property confirming }\end{array}$ & $T_{27}$ & $\begin{array}{l}\text { Test data input finished, confirm } \\
\text { accuracy and effectiveness of data }\end{array}$ \\
\hline$T_{7}$ & $\begin{array}{l}\text { Property confirming succeeds, } \\
\text { technical specification } \\
\text { establishing }\end{array}$ & $T_{28}$ & $\begin{array}{l}\text { Data accuracy and effectiveness } \\
\text { are confirmed, start testing }\end{array}$ \\
\hline$T_{8}$ & $\begin{array}{l}\text { Technical specification } \\
\text { establishing finished, audit } \\
\text { technical specification }\end{array}$ & $T_{29}$ & $\begin{array}{l}\text { Test finished, start the judgment } \\
\text { of test results }\end{array}$ \\
\hline$T_{9}$ & $\begin{array}{l}\text { Technical specification audit } \\
\text { finished, start the application of } \\
\text { development application form }\end{array}$ & $T_{30}$ & $\begin{array}{l}\text { Test results judgment is eligible, } \\
\text { start storing }\end{array}$ \\
\hline$T_{10}$ & $\begin{array}{l}\text { Application of development } \\
\text { application form finished, start } \\
\text { auditing the application form }\end{array}$ & $T_{31}$ & $\begin{array}{l}\text { Warehousing finished, start } \\
\text { collecting all kinds of data } \\
\text { document }\end{array}$ \\
\hline$T_{11}$ & $\begin{array}{l}\text { Auditing application form } \\
\text { finished, start distributing } \\
\text { application }\end{array}$ & $T_{32}$ & $\begin{array}{l}\text { Collection data document } \\
\text { finished, the project comes to end }\end{array}$ \\
\hline$T_{12}$ & $\begin{array}{l}\text { Distributing application finished, } \\
\text { start preparing formula }\end{array}$ & $T_{33}$ & $\begin{array}{l}\text { The audit of project feasibility } \\
\text { analysis failed, research again }\end{array}$ \\
\hline$T_{13}$ & $\begin{array}{l}\text { Formula preparation finished, } \\
\text { start confirming material } \\
\text { property }\end{array}$ & $T_{34}$ & $\begin{array}{l}\text { Project is not feasible, the project } \\
\text { ended, collecting relevant data }\end{array}$ \\
\hline$T_{14}$ & $\begin{array}{l}\text { Material property formula } \\
\text { confirming finished, materials } \\
\text { property formula developing }\end{array}$ & $T_{35}$ & $\begin{array}{l}\text { Performance auditing failed, } \\
\text { back to analysis }\end{array}$ \\
\hline$T_{15}$ & $\begin{array}{l}\text { Material property formula } \\
\text { establishing finished, start } \\
\text { auditing the material formula }\end{array}$ & $T_{36}$ & $\begin{array}{l}\text { The audit of technical } \\
\text { specifications failed, to start } \\
\text { establish again }\end{array}$ \\
\hline$T_{16}$ & $\begin{array}{l}\text { Materials formula audit finished, } \\
\text { start confirming the color } \\
\text { formula of the material }\end{array}$ & $T_{37}$ & $\begin{array}{l}\text { Development application form } \\
\text { approval failed, to apply again }\end{array}$ \\
\hline$T_{17}$ & $\begin{array}{l}\text { Material color formula } \\
\text { confirming finished, start } \\
\text { materials color formula } \\
\text { developing }\end{array}$ & $T_{38}$ & $\begin{array}{l}\text { The audit of material formula } \\
\text { failed, to develop again }\end{array}$ \\
\hline$T_{18}$ & $\begin{array}{l}\text { Material color formula } \\
\text { developing finished, start } \\
\text { auditing materials color formula }\end{array}$ & $T_{39}$ & $\begin{array}{l}\text { The audit of color formula failed, } \\
\text { to develop again }\end{array}$ \\
\hline
\end{tabular}


TABLE 2: Continued.

\begin{tabular}{llcl}
\hline Transition & Meaning of transition & Transition & Meaning of transition \\
\hline$T_{19}$ & $\begin{array}{l}\text { Material color formula auditing } \\
\text { finished, start confirming } \\
\text { technology parameters }\end{array}$ & $T_{40}$ & $\begin{array}{l}\text { The audit of technology } \\
\text { parameters failed, to start } \\
\text { establishing again }\end{array}$ \\
\hline $\begin{array}{l}\text { Technology parameters } \\
\text { confirming finished, start } \\
\text { establishing the technology } \\
\text { parameters }\end{array}$ & $T_{41}$ & $\begin{array}{l}\text { The audit of validity, correctness } \\
\text { of test data failed, reentry again }\end{array}$ \\
\hline$T_{21}$ & $\begin{array}{l}\text { Technology parameters } \\
\text { establishing finished, start } \\
\text { auditing technology parameters }\end{array}$ & $T_{42}$ & $\begin{array}{l}\text { Test results showed the material } \\
\text { did not meet the requirements, } \mathrm{R} \\
\text { \& D again }\end{array}$ \\
\hline
\end{tabular}

TABle 3: Upper and lower time limit corresponding to each Place before being optimized.

\begin{tabular}{|c|c|c|c|c|}
\hline & $E_{1}$ & $E_{2}$ & $L_{1}$ & $L_{2}$ \\
\hline$P_{1}$ & 0 & 0 & 0 & 0 \\
\hline$P_{2}$ & 7 & 9 & 7 & 9 \\
\hline$P_{3}$ & 3 & 5 & 10 & 14 \\
\hline$P_{4}$ & 5 & 6 & 15 & 20 \\
\hline$P_{5}$ & 2 & 3 & 17 & 23 \\
\hline$P_{6}$ & 7 & 9 & 24 & 32 \\
\hline$P_{7}$ & 3 & 4 & 27 & 36 \\
\hline$P_{8}$ & 3 & 5 & 30 & 41 \\
\hline$P_{9}$ & 2 & 3 & 32 & 44 \\
\hline$P_{10}$ & 2 & 3 & 34 & 47 \\
\hline$P_{11}$ & 2 & 3 & 36 & 50 \\
\hline$P_{12}$ & 2 & 3 & 38 & 53 \\
\hline$P_{13}$ & 2 & 3 & 40 & 56 \\
\hline$P_{14}$ & 3 & 4 & 43 & 60 \\
\hline$P_{15}$ & 10 & 12 & 53 & 72 \\
\hline$P_{16}$ & 3 & 5 & 56 & 77 \\
\hline$P_{17}$ & 3 & 4 & 59 & 81 \\
\hline$P_{18}$ & 7 & 9 & 66 & 90 \\
\hline$P_{19}$ & 3 & 5 & 69 & 95 \\
\hline$P_{20}$ & 3 & 5 & 72 & 100 \\
\hline$P_{21}$ & 6 & 8 & 78 & 108 \\
\hline$P_{22}$ & 3 & 4 & 81 & 112 \\
\hline$P_{23}$ & 3 & 4 & 84 & 116 \\
\hline$P_{24}$ & 2 & 3 & 86 & 119 \\
\hline$P_{25}$ & 5 & 7 & 91 & 126 \\
\hline$P_{26}$ & 3 & 4 & 94 & 130 \\
\hline$P_{27}$ & 2 & 3 & 96 & 133 \\
\hline$P_{28}$ & 2 & 3 & 98 & 136 \\
\hline$P_{29}$ & 4 & 6 & 102 & 142 \\
\hline$P_{30}$ & 3 & 5 & 105 & 147 \\
\hline$P_{31}$ & 2 & 3 & 107 & 150 \\
\hline$P_{32}$ & 3 & 5 & 110 & 155 \\
\hline$P_{33}$ & 0 & 0 & 110 & 155 \\
\hline
\end{tabular}

TABLE 4: Simplified upper and lower time limit corresponding to each Place.

\begin{tabular}{|c|c|c|c|c|}
\hline & $E_{1}$ & $E_{2}$ & $L_{1}$ & $L_{2}$ \\
\hline$P_{1}$ & 0 & 0 & 0 & 0 \\
\hline$P_{2}$ & 7 & 9 & 7 & 9 \\
\hline$P_{3}$ & 3 & 5 & 10 & 14 \\
\hline$P_{4}$ & 5 & 6 & 15 & 20 \\
\hline$P_{5}$ & 2 & 3 & 17 & 23 \\
\hline$P_{6}$ & 7 & 9 & 24 & 32 \\
\hline$P_{7}$ & 3 & 4 & 27 & 36 \\
\hline$P_{8}$ & 3 & 5 & 30 & 41 \\
\hline$P_{9}$ & 2 & 3 & 32 & 44 \\
\hline$P_{10}$ & 2 & 3 & 34 & 47 \\
\hline$P_{11}$ & 2 & 3 & 36 & 50 \\
\hline$P_{12}$ & 2 & 3 & 38 & 53 \\
\hline$P_{13}$ & 2 & 3 & 40 & 56 \\
\hline$d_{1}$ & 3 & 4 & 43 & 60 \\
\hline$d_{2}$ & 10 & 12 & 53 & 72 \\
\hline$d_{3}$ & 3 & 5 & 56 & 77 \\
\hline$P_{20}$ & 3 & 5 & 59 & 82 \\
\hline$P_{21}$ & 6 & 8 & 65 & 88 \\
\hline$P_{22}$ & 3 & 4 & 68 & 92 \\
\hline$P_{23}$ & 3 & 4 & 71 & 96 \\
\hline$P_{24}$ & 2 & 3 & 73 & 99 \\
\hline$P_{25}$ & 5 & 7 & 78 & 106 \\
\hline$P_{26}$ & 3 & 4 & 81 & 110 \\
\hline$P_{27}$ & 2 & 3 & 83 & 113 \\
\hline$P_{28}$ & 2 & 3 & 85 & 116 \\
\hline$P_{29}$ & 4 & 6 & 89 & 112 \\
\hline$P_{30}$ & 3 & 5 & 92 & 127 \\
\hline$P_{31}$ & 2 & 3 & 94 & 130 \\
\hline$P_{32}$ & 3 & 5 & 97 & 135 \\
\hline$P_{33}$ & 0 & 0 & 97 & 135 \\
\hline
\end{tabular}




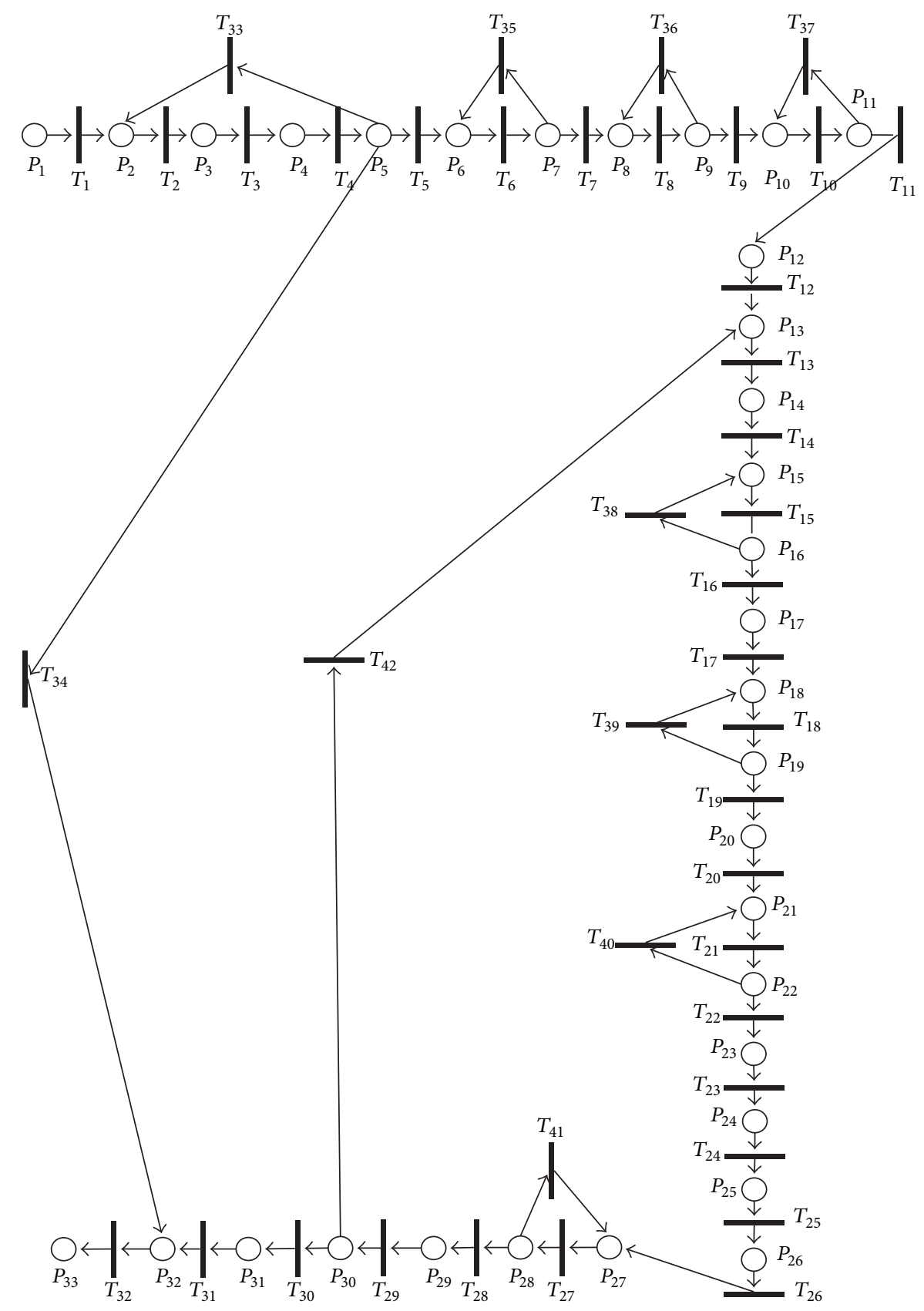

FIGURE 11: Petri net model chart of R\&D production process system.

$d_{3}$ stands for maximum time needed in examination and verification confirming. Because time needed in materials property examination and verification and color examination and verification are the same, materials property examination and verification time can be used.

By comparing this time table to that one before matching process optimizing listed above, it can be known that the minimum time will be shortened 13 days and the maximum time will be shortened 20 days. In a word, process optimizing is obvious for temporal property improved greatly.

\section{Conclusion}

To build new composite materials R\&D process workflow model, the first step is to standardize composite materials $\mathrm{R} \& \mathrm{D}$ process in complex composite materials development and production. By combining two extended net of Petri net and defining Petri net workflow at composite materials $R \& D$ process management system and then analyzing temporal property of entire Petri net, the optimization of workflow can be proposed. Consequently, temporal property 


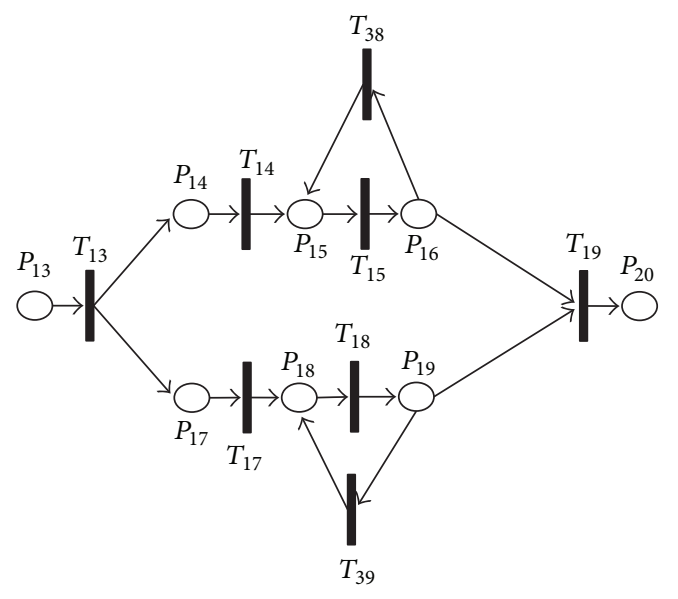

FIGURE 12: Optimized Petri net model of matching process.

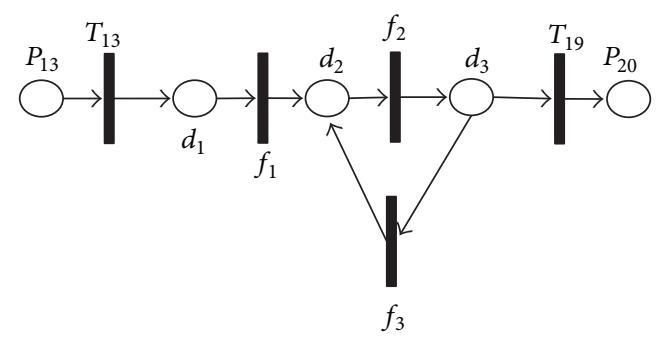

FIGURE 13: Simplified model graph of optimized matching process Petri net.

of entire workflow net can be optimized. After being successfully applied in $\mathrm{R} \& \mathrm{D}$ process management in a materials enterprise, the system did improve developing ability and efficiency for new products, demonstrating its availability.

\section{Acknowledgments}

This work was supported in part by NSFC (Project no. 41101454), the Grand Science and Technology Program Shanghai China (no. 11510500400, no. 13111101303), and Industrial Innovation Grand Projects (no. 07CH-008).

\section{References}

[1] Y.-C. Chen, M.-L. Yeh, C.-L. Hong, and C.-T. Chang, "Petri-net based approach to configure online fault diagnosis systems for batch processes," Industrial \& Engineering Chemistry Research, vol. 49, no. 9, pp. 4249-4268, 2010.

[2] M. Sanjin, M. Milan, and V. Slako, "A fuzzy Petri net model to estimate train delays," Simulation Modelling Practice and Theory, vol. 33, pp. 144-157, 2013.

[3] H.-H. Chou and C.-T. Chang, "Petri-net-based strategy to synthesize the operating procedures for cleaning pipeline networks," Industrial \& Engineering Chemistry Research, vol. 44, no. 1, pp. 114-123, 2005.

[4] M. Giovanni, B. Maurizio, and C. F. Emanuele, "Supply chain modeling and managing, using timed coloured Petri nets: a case study," International Journal of Production Research, vol. 50, no. 16, pp. 4718-4733, 2012.

[5] N. Balasubramanian, C.-T. Chang, and Y.-F. Wang, "Petri-net models for risk analysis of hazardous liquid loading operations," Industrial \& Engineering Chemistry Research, vol. 41, no. 19, pp. 4823-4836, 2002.

[6] P. Chrzastowski-Wachtel, B. Benatallah, R. Hamadi et al., "A top-down Petri net-based approach for dynamic workflow modeling," in Business Process Management, W. M. P. van der Aalst, Ed., vol. 2678 of Lecture Notes in Computer Science, pp. 336-353, Springer, Berlin, Germany, 2003.

[7] C. Lin and Y. Qu, "Temporal inference of workflow systems based on time petri nets: quantitative and qualitative analysis," International Journal of Intelligent Systems, vol. 19, no. 5, pp. 417442, 2004.

[8] J. Hao, Y. S. Dong, and J. Z. Luo, "An effective approach to verify the correctness of workflow process models based on Petri net," Journal of Southeast University, vol. 18, no. 4, pp. 361-366, 2002.

[9] W. M. P. van der Aalst, "The application of Petri nets to workflow management," Journal of Circuits, Systems and Computers, vol. 8, no. 1, pp. 21-66, 1998.

[10] J. Hao, D. Yisheng, and L. Junzhou, "Research on Petri net based modeling and analyzing methods for workflow process," Joumal of Southeast University, vol. 2, pp. 68-70, 2000.

[11] H. Hu and Z. Li, "Modeling and scheduling for manufacturing grid workflows using timed Petri nets," International Journal of Advanced Manufacturing Technology, vol. 42, no. 5-6, pp. 553568, 2009.

[12] J.-W. Lai, C.-T. Chang, and S.-H. Hwang, "Petri-net based binary integer programs for automatic synthesis of batch operating procedures," Industrial \& Engineering Chemistry Research, vol. 46, no. 9, pp. 2797-2813, 2007.

[13] Y.-F. Wang and C.-T. Chang, "Petri-net-based deductive reasoning strategy for fault identification in batch processes," Industrial \& Engineering Chemistry Research, vol. 43, no. 11, pp. 2704-2720, 2004.

[14] R. Yongjie, Multi-Agent Workflow Model (MAWM): a workflow model designed for Chinese business processes [a thesis submitted in partial fulfillment of the requirements for the degree of doctor of philosophy in systems engineering and engineering management], The Chinese University of Hong Kong, 2001.

[15] T. F. Laurentiu and B. Corina, "Priority workflow nets," IEEE Transactions on Systems Man Cybernetics-Systems, vol. 43, no. 2, pp. 402-415, 2013.

[16] L. He, C. Huang, K. Duan et al., "Modeling and analyzing the impact of authorization on workflow executions," Future Generation Computer Systems, 2012.

[17] J. R. Fanchi, "Flow modeling workflow," Journal of Petroleum Science and Engineering, vol. 79, no. 1-2, pp. 54-57, 2011.

[18] C. Wibowo and K. M. Ng, "Workflow for process synthesis and development: crystallization and solids processing," Industrial \& Engineering Chemistry Research, vol. 41, no. 16, pp. 3839$3848,2002$.

[19] Y. Lu, L. Zhang, and J. Sun, "Using colored Petri nets to model and analyze workflow with separation of duty constraints," International Journal of Advanced Manufacturing Technology, vol. 40, no. 1-2, pp. 179-192, 2009.

[20] X. Jun, D. Hai-hong, G. Yun-feng et al., "Workflow modeling and time performance analysis based on Petri net," Journal of Jilin University, vol. 27, no. 1, pp. 104-112, 2009. 
[21] M. Dong and F. F. Chen, "Petri net-based workflow modelling and analysis of the integrated manufacturing business processes," International Journal of Advanced Manufacturing Technology, vol. 26, no. 9-10, pp. 1163-1172, 2005.

[22] B. Behnam, M. Homayun, and B. H. Solving, "Flexible job-shop scheduling problem using gravitational search algorithm and colored Petri net," Journal of Applied Mathematics, vol. 2012, Article ID 651310, 20 pages, 2012.

[23] S. Balaguer, T. Chatain, and S. Haar, "A concurrency-preserving translation from time Petri nets to networks of timed automata," Formal Methods in System Design, vol. 40, no. 3, pp. 330-355, 2012.

[24] M. Kloetzer, C. Mahulea, C. Belta, and M. Silva, "An automated framework for formal verification of timed continuous petri nets," IEEE Transactions on Industrial Informatics, vol. 6, no. 3, pp. 460-471, 2010.

[25] L. Yanfu, Z. Enrico, and L. Yanhui, "A multistate physics model of component degradation based on stochastic Petri nets and simulation," IEEE Transactions on Reliability, vol. 61, no. 4, pp. 921-931, 2012.

[26] D. Lefebvre, "About the stochastic and continuous Petri nets equivalence in the long run," Nonlinear Analysis: Hybrid Systems, vol. 5, no. 3, pp. 394-406, 2011.

[27] G. Daniel, R. Jan, and W. Matthias, "Modeling group scheduling problems in space and time by timed Petri nets," Fundamenta Informaticae, vol. 122, no. 4, pp. 297-313, 2013.

[28] L, W. S. Miao, and L. Zhiwu, "Supervisor reconfiguration for deadlock prevention by resources reallocation," Journal of Applied Mathematics, vol. 2013, Article ID 315894, 11 pages, 2013. 


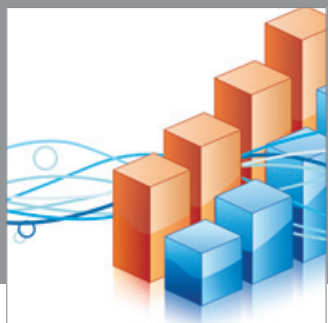

Advances in

Operations Research

mansans

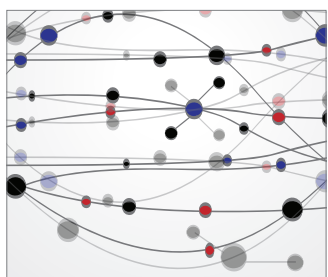

The Scientific World Journal
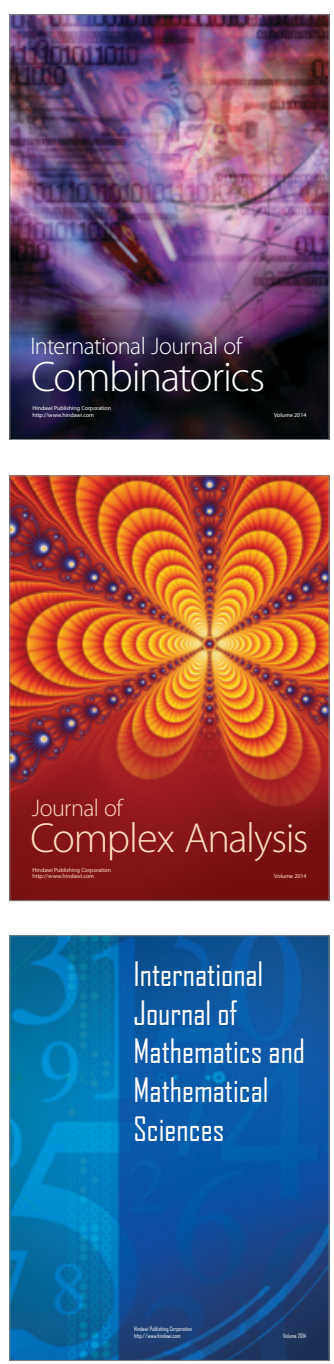
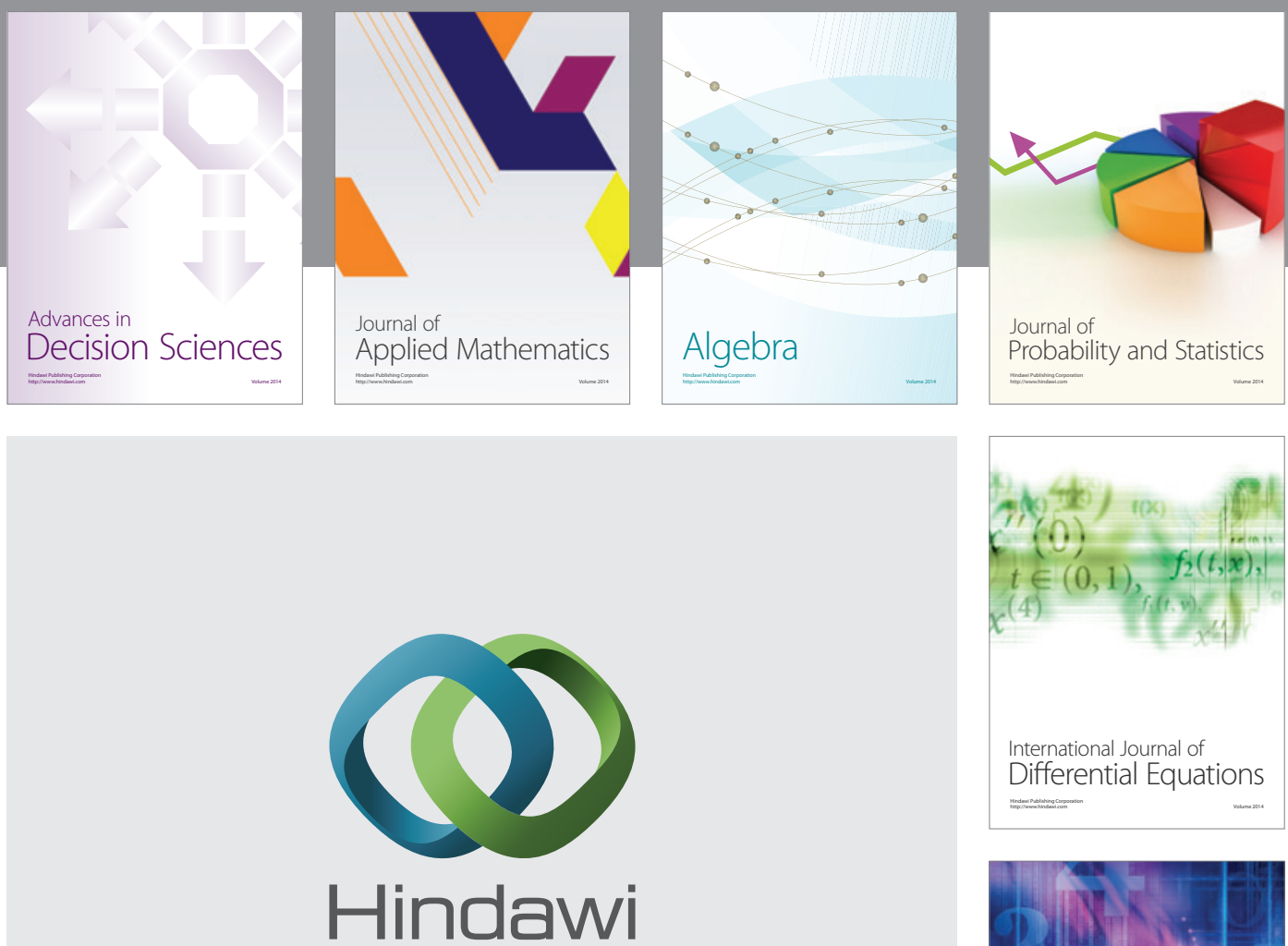

Submit your manuscripts at http://www.hindawi.com
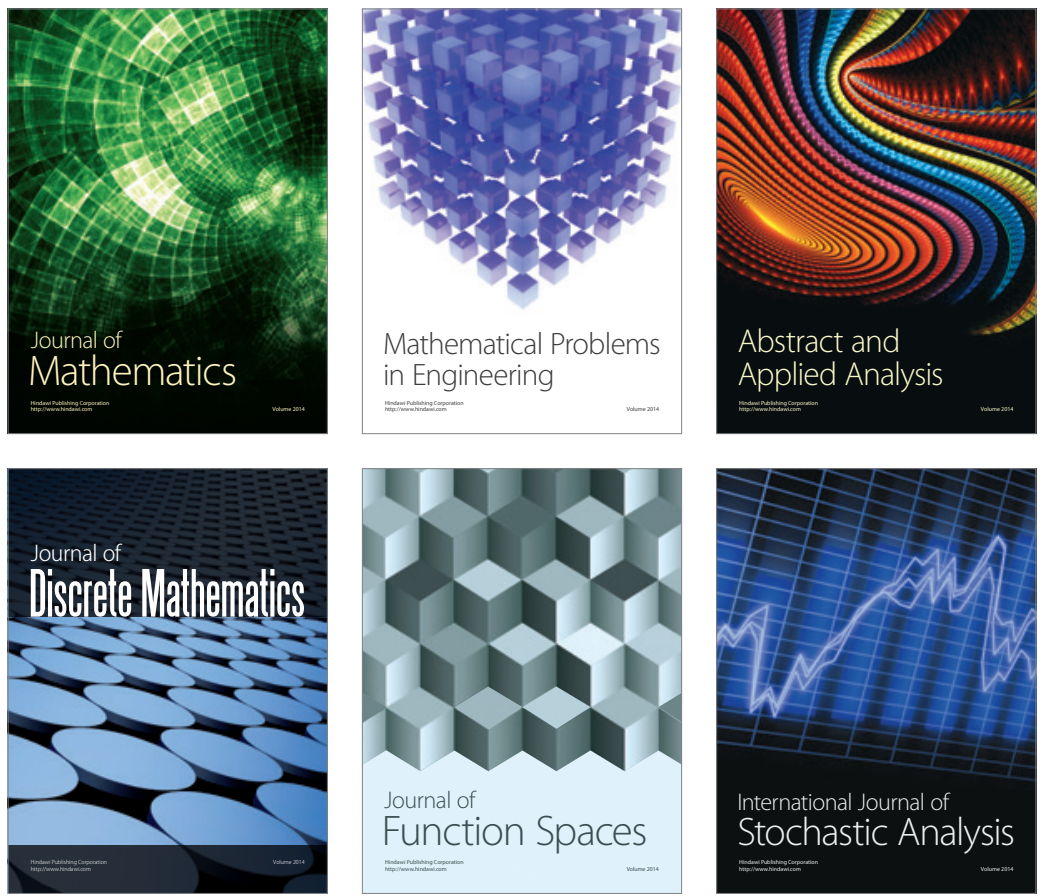

Journal of

Function Spaces

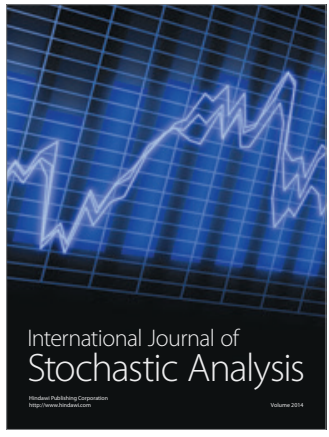

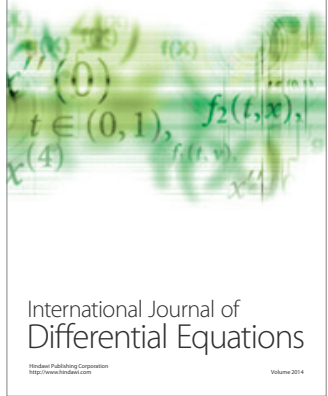
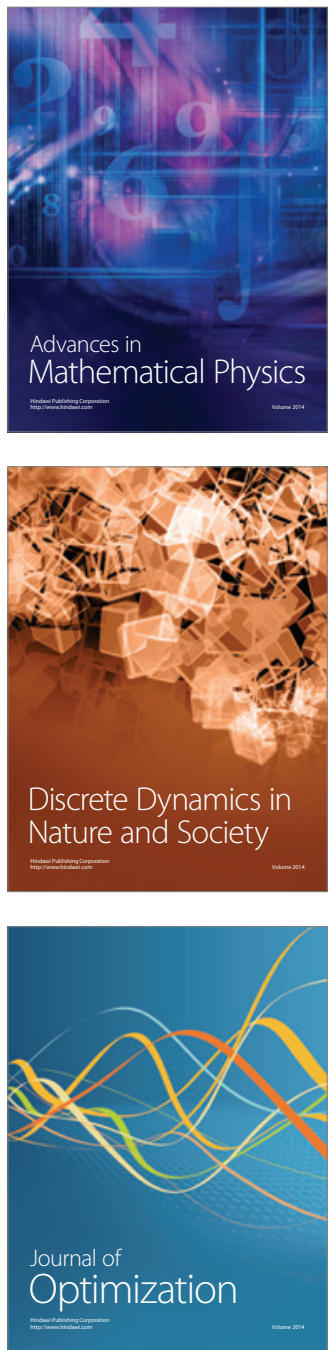